\title{
EFFECTS OF PRE-EVENT MASSAGE ON ANXIETY AMONG NIGERIA NATIONAL TEAM FOOTBALL PLAYERS: A PILOT STUDY
}

original paper

( ) University School of Physical Education in Wroclaw

DOI: https://doi.org/10.5114/hm.2019.85090

\author{
ABDULSALAM KAYODE SHUIABU ${ }^{1}$, BASHIR BELLO ${ }^{2}$ \\ ${ }^{1}$ School of Life, Sport and Social Science, Edinburgh Napier University, Edinburgh, United Kingdom \\ ${ }^{2}$ Physiotherapy Department, Faculty of Allied Health Sciences, Bayero University Kano, Kano, Nigeria
}

\section{ABSTRACT}

Purpose. The purpose of the study was to examine the effect of pre-event massage on anxiety among Nigeria national team football players during the World Cup matches. As secondary outcomes, the effects of massage on blood pressure (BP) and heart rate (HR) were analysed.

Methods. Overall, 17 World Cup players had massage both less and more than 24 hours prior to matches. Holey and Cook massage protocol was used. The Mental Readiness Form version 3 (MRF-3) was applied to assess anxiety level while an electronic BP monitoring kit served to monitor BP and HR before and after massage. Inferential statistic of paired $t$-test was carried out for the effect of massage on BP and HR.

Results. The result of the study showed a significant difference in anxiety after massage with $p<0.05$ at periods less and more than 24 hours before the matches. There was also a significant difference between the pre- and post-massage BP and HR at a period less and more than 24 hours before the matches $(p<0.05)$.

Conclusions. Pre-event massage before World Cup matches reduced anxiety among Nigeria national team football players. Key words: massage, anxiety, footballers, competition, blood pressure, heart rate

\section{Introduction}

Anxiety is an emotional affection that is experienced by athletes in the course of participation in competitive sporting events [1]. It is believed to be influenced by the magnitude of competition, inability to predict the outcome, and the genetic factors of the competing individual [2]. Anxiety has been observed to be higher in intensity among athletes at a period of 1 week or less preceding a major sporting event and to affect all athletes across all sports, irrespective of their level of experience [3]. Anxiety in a competing athlete is manifested at both cognitive and somatic levels. It is displayed by discomfort, uncoordinated movements, and general tension in the body, making any medium that can calm the triggered effects useful.

Pre-competition anxiety is said to be one main psychological factor that influences an athlete's performance and game outcomes. According to Kremer et al. [4], the reasons why athletes become stressed before a competition may be the pressure of being observed, fear of failure, the perception of their own abilities based on a previous performance, beliefs regarding the opposition, or the perceived importance of the competition. The more important the contest, the greater the stress, and the more likely it is that a competitor will be prone to anxiety.

Football is a game of strength, speed, power, and endurance that is exhibited during the play. The major international competition in football is the World Cup, involving millions of dollars in reward of match bonuses and won trophies. It is the most prestigious football tournament in the world, as well as the most widely viewed and followed sporting event [5]. Thus, increased anxiety among World Cup football players cannot be ruled out.

The few methods that have been adopted in the management of sports-induced anxiety are visualization, counselling, and relaxation techniques which may be achieved by massage [6].

Correspondence address: Bashir Bello, Physiotherapy Department, Faculty of Allied Health Sciences, Bayero University Kano, PMB, 3011, Kano, Nigeria, e-mail: bbello.pth@buk.edu.ng

Received: October 25, 2018

Accepted for publication: April 3, 2019

Citation: Shuiabu AK, Bello B. Effects of pre-event massage on anxiety among Nigeria national team football players: a pilot study. Hum Mov. 2019;20(4):46-51; doi: https://doi.org/10.5114/hm.2019.85090. 
Massage is a process of manipulating the soft tissues of the body by a qualified professional with the aims of reliving pain, increasing the joint range of motion, improving soft tissue mobility, inducing general body relaxation, and enhancing performance. It is one of the most utilised procedures in preparation for sporting activities. Massage helps not only improve the physiological properties of the muscles; most athletes report a feeling of pure relaxation, reduced anxiety, enhanced attentiveness, and improved mood following a massage [7].

However, even with the claimed effect of massage and its common application in sports, there is a dearth of studies on the use of massage for anxiety management among football players competing in the World Cup. The majority of previous studies on the effect of massage were carried out in clinical settings to control anxiety in various medical and surgical conditions [8-10]. Only 3 studies observed the effects of massage on the mood and confidence among sports-related participants [11-13], although they were all marred by various methodological flaws that involved non-standardisation of massage protocols and lack of valid anxiety assessment tools. Also, the subjects were not participating in competitive sports when the studies were carried out. Therefore, there is a need to observe the effect of massage on the anxiety level of athletes in competitive sports, particularly among footballers playing in the World Cup, as it is the highest competitive stage for football players. Hence, the study was designed to examine the effects of pre-event massage on the anxiety level and to evaluate the impact of massage on cardiovascular variables associated with anxiety among Nigeria national team football players.

\section{Material and methods}

\section{Research design}

A pretest-posttest experimental research design was applied.

\section{Participants}

The pool of all Nigeria senior national football team players who participated in pre-World Cup and 2014 FIFA World Cup matches were involved in this study. The participants were included only if they were not under any known emotional stress apart from the competition-induced anxiety. Those who had been managed for anxiety through medication or other means prior to the commencement of the study and still remained under the treatment were excluded.

\section{Selection/sampling technique}

A purposive sampling technique was adopted in the choice of the team. Potentially all team players were targeted for the recruitment. All participants had the massage both less than 24 hours and more than 24 hours before the matches.

\section{Materials and instruments}

Mental Readiness Form version 3 (MRF-3) for assessment of competitive state anxiety was used to evaluate anxiety. The major reason for this choice was the need for quick measurement without interference with the athletes' activities. MFR-3 is a reliable and valid means of measuring anxiety and self-confidence in competitive sporting environment [14]. Validity analysis illustrated several significant relationships (coefficients ranging from 0.30 to 0.80 ) between MRF-3 and the Competitive State Anxiety Inventory-2 (CSAI-2) [1].

All the components of MRF-3 were kept anonymous through the coding of the assessment form. The same form contained pre-massage cardiovascular variables and the anxiety measuring scale at the front page. At the back page were the post-massage anxiety items and the cardiovascular variables. The format of design was to allow for the record of actual anxiety state without reference to the initial value taken. This was based on the assumption that the selection of the post-massage anxiety level would be influenced by allowing the participants to view the pre-massage anxiety value.

A battery-powered analogue table clock was used in monitoring the time spent on each part during massage. The sound generated from the clock also served as a metronome.

An electronic blood pressure (BP) monitoring kit, upper arm BP monitor model Lifemax $1222 \mathrm{P} / \mathrm{N}$ : 323101951 VER: 001 served to monitor the heart rate (HR), systolic BP (SBP), and diastolic BP (DBP) of the participants before and after massage. The guidelines of the European Society of Hypertension were strictly followed [15].

A massage table was used to position the players for massage (in both prone and supine lying). The applied Vaseline massage oil has no pharmaceutical effect and no allergic response was triggered after its use.

\section{Data collection procedure}

At the beginning of the massage session, the participant lay in supine position on a couch for 5 minutes. 
A. Shuiabu, B. Bello, Effects of pre-event massage on anxiety in football players

Then he had the BP and HR assessed and was asked to complete the MRF-3. This was followed by massage for 45-50 minutes at the rate of 25-30 strokes per minute at a moderate depth (grade 2), in accordance with the relaxation massage protocols described by Holey and Cook [16].

\section{Massage protocol}

The massage room was quiet and no music played. The temperature of the room was maintained at $23^{\circ} \mathrm{C}$ throughout. The massage was carried out by a certified physiotherapist with 8 years of experience in sport massage.

Below is the detailed description on how the various massage techniques were applied:

- Quadriceps: stroking (30 seconds), effleurage (1 minute), kneading (2 minutes), effleurage (1 minute), and stroking (30 seconds).

- Shin: stroking (30 seconds), effleurage (1 minute), kneading (1 minute), and stroking (30 seconds).

- Calf: stroking (30 seconds), effleurage (1 minute), kneading (1 minute), effleurage (1 minute), and stroking (30 seconds).

- Hamstring: stroking (30 seconds), effleurage (1 minute), kneading (2 minutes), effleurage (1 minute), and stroking (30 seconds).

- Back: stroking (30 seconds), effleurage (1 minute), kneading (2 minutes), frictional (1 or 2 minutes), wringing (1 minute), effleurage (1 minute), and stroking (30 seconds).

On completion of the massage session, the participants were allowed to rest for another 5 minutes in supine lying. This was followed by the measurements of the SBP, DBP, HR, and MRF-3 by the same individual that coordinated all the assessments for blinding purpose.

\section{Variables}

A. Independent variable: the massage protocol and the period of massage.

B. Dependent variables:

1. anxiety scores (somatic, cognitive, and self-confidence);

2. SBP, DBP, and HR.

\section{Data analysis}

Descriptive statistics in the form of mean, median, and standard deviation were used to summarize the data (age, anxiety, and BP). Inferential statistic in the form of paired sample $t$-test was carried out for the effect of massage on the SBP, DBP, and HR. The effect of massage on anxiety was analysed by the use of Wilcoxon signed rank test. The significance level was set at 0.05 and the analysis was conducted with the IBM SPSS software version 20.

\section{Ethical approval}

The research related to human use has complied with all the relevant national regulations and institutional policies, including the National Health Council resolution (466/2012), has followed the tenets of the Declaration of Helsinki, and has been approved by the Research Ethics and Governance Committee of Edinburgh Napier University.

\section{Informed consent}

Informed consent was obtained from all individuals included in this study and data collection was performed with the consent of the team executives.

\section{Results}

The participants in this study were all males, with age range of $21-33$ years $(25.47 \pm 3.84$ years).

The results showed a statistically significant difference in the pre-massage SBP, DBP, and HR when compared with the post-massage variables, with $p<$ 0.05 , at the period less than 24 hours before the matches played at the World Cup, with a large effect size (Table 1). There was a reduction of $6.47 \mathrm{~mm} \mathrm{Hg}$ in the SBP after massage (95\% confidence interval [CI]: 5.06-7.88; $t(16)=9.73$ ) when compared with the SBP before the massage, also with a large effect size $(d=0.83)$. The result also revealed a statistically significant difference in the pre-massage DBP when compared with the post-massage DBP, with $p<0.05$. The reduction of $5.59 \mathrm{~mm} \mathrm{Hg}$ in the DBP was found $(95 \%$ CI: 2.75-8.42; $t(16)=9.73)$ after massage when compared with DBP before the massage. There was a very large effect size $(d=1.31)$ and a minimal percentage coefficient of variation $(\% \mathrm{CV})$ between the pre-massage SBP, DBP, and HR when compared with the post-massage variables (Table 1).

The study also showed a statistically significant difference in pre-massage HR when compared with post-massage HR, with $p<0.05$. An increase of 4.24 $\mathrm{bpm}$ in the HR was found (95\% CI: 6.66-1.81; $t(16)=$ 3.70) when compared with the HR before the massage, with a moderate effect size $(d=0.52)$.

The study results showed a significant difference in the cognitive anxiety, somatic anxiety, and self-con- 
Table 1. Comparison between the mean pre- and post-massage cardiovascular variables at the period less than 24 hours before the matches played at the World Cup

\begin{tabular}{lrcrrrr} 
Variables & $\begin{array}{r}\text { Pre-massage } \\
(\text { mean } \pm S D)\end{array}$ & $\% \mathrm{CV}$ pre-massage & $\begin{array}{r}\text { Post-massage } \\
(\text { mean } \pm S D)\end{array}$ & \%CV post-massage & $p$ & $d$ \\
\hline SBP $(\mathrm{mm} \mathrm{Hg})$ & $122.29 \pm 8.64$ & 7.07 & $115.82 \pm 7.00$ & 6.04 & $<0.001^{*}$ & 0.82 \\
DBP (mm Hg) & $72.95 \pm 4.50$ & 6.17 & $67.24 \pm 4.20$ & 6.25 & $<0.001^{*}$ & 1.31 \\
HR (bpm) & $60.95 \pm 7.22$ & 11.85 & $63.12 \pm 9.10$ & 14.42 & $0.002^{*}$ & 0.26 \\
\hline
\end{tabular}

$S D$ - standard deviation, \%CV - percentage coefficient of variation, SBP - systolic blood pressure,

$\mathrm{DBP}$ - diastolic blood pressure, HR - heart rate

* significant at $p<0.05$

Table 2. Comparison between pre- and post-massage anxiety components at the period less than 24 hours before the matches played at the World Cup

\begin{tabular}{lccccc}
\hline Variables (pre/post massage) & Positive ranks & Negative ranks & $z$ & $r$ & $p$ \\
\hline Cognitive anxiety & 0.00 & 136.00 & 3.598 & 0.90 & $0.000^{*}$ \\
Somatic anxiety & 0.00 & 78.00 & 3.176 & 0.79 & $0.001^{*}$ \\
Self-confidence & 13.00 & 92.00 & 2.675 & 0.67 & $0.007^{*}$ \\
\hline
\end{tabular}

* significant at $p<0.05$

Table 3. Comparison between the mean pre- and post-massage cardiovascular variables at the period more than 24 hours before the matches played at the World Cup

\begin{tabular}{lrccccc}
\hline Variables & $\begin{array}{c}\text { Pre-massage } \\
(\text { mean } \pm S D)\end{array}$ & \%CV pre-massage & $\begin{array}{c}\text { Post-massage } \\
(\text { mean } \pm S D)\end{array}$ & \%CV post-massage & $p$ & $d$ \\
\hline SBP $(\mathrm{mm} \mathrm{Hg})$ & $120.00 \pm 6.38$ & 5.32 & $115.82 \pm 4.94$ & 4.27 & $0.009^{*}$ & 0.73 \\
DBP $(\mathrm{mm} \mathrm{Hg})$ & $71.18 \pm 6.08$ & 8.54 & $65.18 \pm 6.74$ & 10.34 & $<0.001^{*}$ & 0.93 \\
HR (bpm) & $59.24 \pm 9.15$ & 15.45 & $61.76 \pm 10.63$ & 17.21 & 0.224 & 0.25 \\
\hline
\end{tabular}

$S D$ - standard deviation, \%CV - percentage coefficient of variation, SBP - systolic blood pressure,

DBP - diastolic blood pressure, HR - heart rate

* significant at $p<0.05$

fidence after massage, with $p<0.05$, at the period less than 24 hours before the matches played at the World Cup (Table 2).

All of the participants reported a reduction in cognitive anxiety after massage, without any negative effect noticed in any of the subjects, with a large effect $(r=0.90)$.

The rating of somatic anxiety showed that 12 participants had a reduction in their anxiety after massage, with no subject reporting a negative effect. Five athletes observed no difference in their somatic anxiety before and after massage. There was a large effect from the massage $(r=0.92)$.

Rating the self-confidence level, 12 participants reported an improvement after massage, while 2 subjects observed a reduction in self-confidence after massage. The remaining 3 athletes displayed no dif- ference in self-confidence before and after massage. There was large effect from the massage $(r=0.72)$.

Table 3 shows a statistically significant difference in pre-massage SBP and DBP only, without any significant difference in HR as compared with the post-massage variables, with $p<0.05$.

The reduction in the SBP of $4.18 \mathrm{~mm} \mathrm{Hg}$ was found $(95 \%$ CI: $1.22-7.13 ; t(16)=3.00)$ after massage when compared with the SBP before the massage. There was medium effect size $(d=0.74)$.

Furthermore, a reduction of $6.00 \mathrm{~mm} \mathrm{Hg}$ in DBP was observed (95\% CI: 4.07-7.93; $t(16)=6.58)$ after massage when compared with the DBP before the massage. This showed a large effect size $(d=0.94)$.

Also, an increase in the HR of $2.53 \mathrm{bpm}$, which was not significant, was noted (95\% CI: 6.77-1.71; $t(16)=1.27)$ after massage when compared with the 
A. Shuiabu, B. Bello, Effects of pre-event massage on anxiety in football players

Table 4. Comparison between pre- and post-massage anxiety components at the period more than 24 hours before the matches played at the World Cup

\begin{tabular}{lcccrr}
\hline Variables (pre/post massage) & Positive ranks & Negative ranks & $z$ & $r$ & $p$ \\
\hline Cognitive anxiety & 0.00 & 136.00 & 3.656 & 0.91 & $<0.001^{*}$ \\
Somatic anxiety & 1.00 & 35.00 & 2.422 & 0.61 & $0.015^{*}$ \\
Self-confidence & 00.00 & 66.00 & 3.207 & 0.80 & $0.001^{*}$ \\
\hline
\end{tabular}

* significant at $p<0.05$

HR before the massage. There was a very small effect size $(d=0.26)$ and a minimal \%CV between the premassage SBP, DBP, and HR when compared with the post-massage variables (Table 3 ).

The results of the study revealed a significant difference in cognitive anxiety, somatic anxiety, and self-confidence after massage, with $p<0.05$ (Table 4). There was large effect from the massage $(r=0.94)$.

Similarly, a significant difference in somatic anxiety was observed after massage, with $p<0.05$. The results presented a large effect $(r=0.92)$.

Finally, the results available in Table 4 indicate a significant difference in self-confidence, with $p<0.05$. There was also a large effect $(r=0.97)$.

\section{Discussion}

According to Ford et al. [17], competitive sports have the potential for high levels of stress and anxiety, and practicing and employing a range of physiological and psychological strategies can be beneficial in anxiety management.

This study examined the effects of pre-event massage on anxiety and cardiovascular variables among Nigeria national team football players. The main finding of the study was that there was a significant benefit of pre-event massage administered by a sport physiotherapist at a period less or more than 24 hours prior to the World Cup matches played, in terms of reduction in anxiety levels and cardiovascular variables. The obtained reductions in BP were in line with those in the previous studies [18, 19]. The only contrary finding in our study was the change observed in HR, which showed no significant difference between the pre- and post-event values. This might be due to less pressure on the initial phase of the World Cup before the knock-out stage, which may put more burden on the players, increasing the arousal impact, raising the BP, and hence making the baseline BP value higher [20]. Therefore, massage at this stage turns out very beneficial in calming the anxious players, as evidenced in the findings of this study.
The reduced SBP and DBP observed in the period more than 24 hours before the match are similar to the findings on the cardiovascular variables at the period less than 24 hours before the match. However, the mean of cardiovascular variables at the period more than 24 hours appears to be the lowest when compared with the other stage. This is possible because the intensity of the arousal stimulated by the anxiety at this period is lower, particularly in the case of cognitive and somatic anxiety, when compared with the less than 24 hours period. This might lower the stimulation of the impulse leading to the sympathetic effect, hence the reduced cardiovascular variables observed. Therefore massage should be administered to players more than 24 hours before the competition.

The reduction in anxiety noted from the reduced cognitive and somatic anxiety with increased selfconfidence in this period is similar to the findings in the studies that observed the effect of massage on anxiety. However, the baseline range of anxiety perceived ratings is lower at this period when compared with the period less than 24 hours to the match at the World Cup. This is because the frequency of cognitive anxiety prior to the game at this period might be lower than the one less than 24 hours to the game, leading to a lower level of arousal. This study presents some evidence of benefit of pre-event massage on anxiety among professional football players, especially at a period more than 24 hours before a competitive match.

A major limitation of this study was lack of participants' out of competition baseline anxiety data for comparison with the competitive state, as well as lack of external validity of the massage protocol.

To our knowledge, no other studies have evaluated the effect of pre-event massage during a competitive state. Sports physiotherapists often use massage to relieve pain and muscle stretches before any game. It is very important for sports physiotherapist to recognize other modalities they could apply to improve performance among sportsmen by reducing anxiety prior to the event. The findings of this study provide ad- 
ditional modality in reducing pre-event anxiety among footballers during a competitive game.

\section{Conclusions}

From the findings of this study, it was concluded that pre-event massage prior to World Cup football matches had a positive effect in reducing anxiety and cardiovascular variables among Nigeria national team football players. The results should be considered as preliminary given that the sample was small and there was no control group or no follow-up.

\section{Disclosure statement}

No author has any financial interest or received any financial benefit from this research.

\section{Conflict of interest}

The authors state no conflict of interest.

\section{References}

1. Cox RH. Sport psychology: concepts and applications, $7^{\text {th }}$ ed. Boston: McGraw-Hill; 2007.

2. Jarvis M. Sport psychology: a student's handbook. London: Routledge; 2006.

3. Hanton S, Thomas O, Maynard I. Competitive anxiety responses in the week leading up to competition: the role of intensity, direction and frequency dimensions. Psychol Sport Exerc. 2004;5(2):169-181; doi: 10.1016/ S1469-0292(02)00042-0.

4. Kremer J, Moran A, Walker G, Craig C. Key concepts in sport psychology. London: SAGE Publications Ltd; 2012.

5. FIFA. FIFA Survey: approximately 250 million footballers worldwide. FIFA; 2001. Available from: https://www.fifa.com/about-fifa/who-we-are/news/fifasurvey-approximately-250-million-footballers-worldwide-88048.

6. Athan AN, Sampson UI. Coping with pre-competitive anxiety in sports competition. Eur J Nat Appl Sci. 2013; 1(1):1-9.

7. Boguszewski D, Szkoda S, AdamczykJG, Białoszewski D. Sports massage therapy on the reduction of delayed onset muscle soreness of the quadriceps femoris. Hum Mov. 2014;15(4):234-237; doi: 10.1515/humo2015-0017.

8. Cooke M, Holzhauser K, Jones M, Davis C, Finucane J. The effect of aromatherapy massage with music on the stress and anxiety levels of emergency nurses: comparison between summer and winter. J Clin Nurs. 2007;16(9):1695-1703; doi: 10.1111/j.1365-2702.2007. 01709.x.

9. Davis C, Cooke M, Holzhauser K, Jones M, Finucane J. The effect of aromatherapy massage with music on the stress and anxiety levels of emergency nurses. Aus- tralas Emerg Nurs J. 2005;8(1-2):43-50; doi: 10.1016/ j.aenj.2005.05.001.

10. Büyükyılmaz F, Aştı T. The effect of relaxation techniques and back massage on pain and anxiety in Turkish total hip or knee arthroplasty patients. Pain Manag Nurs. 2013;14(3):143-154; doi: 10.1016/j.pmn.2010. 11.001.

11. Arroyo-Morales M, Fernández-Lao C, Ariza-García A, Toro-Velasco C, Winters M, Díaz-Rodríguez L, et al. Psychophysiological effects of preperformance massage before isokinetic exercise. J Strength Cond Res. 2011;25(2):481-488; doi: 10.1519/JSC.0b013e3181e $83 \mathrm{a} 47$.

12. Dawson KA, Dawson L, Thomas A, Tiidus PM. Effectiveness of regular proactive massage therapy for novice recreational runners. Phys Ther Sport. 2011;12(4):182187; doi: 10.1016/j.ptsp.2011.02.007.

13. Jooste K, Khumalo V, Maritz J. Sportmen's experiences at a somatology clinic receiving a sport message. Health SA Gesondheid. 2013;18(1):1-9; doi: 10.4102/ hsag.v18i1.637.

14. Krane V. The Mental Readiness Form as a measure of competitive state anxiety. Sport Psychol. 1994;8(2): 189-202; doi: 10.1123/tsp.8.2.189.

15. Parati G, Stergiou GS, Asmar R, Bilo G, de Leeuw P, Imai Y, et al. European Society of Hypertension guidelines for blood pressure monitoring at home: a summary report of the Second International Consensus Conference on Home Blood Pressure Monitoring. J Hypertens. 2008;26(8):1505-1526; doi: 10.1097/HJH. 0b013e328308da66.

16. Holey E, Cook E. Evidence-based therapeutic massage: a practical guide for therapists. London: Churchill Livingstone; 2011.

17. Ford JL, Ildefonso K, Jones ML, Arvinen-Barrow M. Sport-related anxiety: current insights. Open Access J Sports Med. 2017;8:205-212; doi: 10.2147/OAJSM. S125845.

18. Kaye AD, Kaye AJ, Swinford J, Baluch A, Bawcom BA, Lambert TJ, et al. The effect of deep-tissue massage therapy on blood pressure and heart rate. J Altern Complement Med. 2008;14(2):125-128; doi: 10.1089/ acm.2007.0665.

19. Ejindu A. The effects of foot and facial massage on sleep induction, blood pressure, pulse and respiratory rate: crossover pilot study. Complement Ther Clin Pract. 2007;13(4):266-275; doi: 10.1016/j.ctcp.2007.03.008.

20. Lundqvist C, Kenttä G, Raglin JS. Directional anxiety responses in elite and sub-elite young athletes: intensity of anxiety symptoms matters. Scand J Med Sci Sports.2011;21(6):853-862; doi:10.1111/j.1600-0838. 2010.01102.x. 